\title{
Non-isothermal Diffusion of Water Vapour in Porous Building Materials
}

T. Ficker, Z. Podešvová

Non-isothermal diffusion is analysed using Fick's laws. The exact relations for non-isothermal diffusion flux and partial pressure profiles in porous building materials are derived and discussed.

Keywords: Fick's laws, non-isothermal diffusion, partial pressure profile.

\section{Introduction}

In the national thermal standards of various countries [1], [2] there are diffusion data that were measured under some standard isothermal and isobaric conditions, e.g. for temperature $T_{\mathrm{a}}=283 \mathrm{~K}$ and atmospheric pressure $p_{\mathrm{a}}=98066.5 \mathrm{~Pa}$. The diffusion data determined under such conditions are often used in cases for which neither isothermal nor isobaric conditions are fulfilled. For example, when the condensation of water vapour in building envelopes is estimated, an isothermal state can rarely be assumed. The condensation is usually estimated for winter conditions, when the temperatures of interior $T_{1}$ and exterior $T_{2}$ are quite different. In this case the effective temperature $T^{*}=\left(T_{1}+T_{2}\right) / 2$ is introduced and is assumed to be close to the standard temperature $T_{\mathrm{a}}=283 \mathrm{~K}$. It is assumed that the effective temperature $T^{*}$ is common for the whole envelope, i.e., it is the isothermal approximation with the single temperature $T^{*}$ that enables numerical estimation of the non-isothermal condensation of water vapour diffusing through the envelope to be performed. For this purpose the coefficient of diffusion permeability $\delta$ is defined as follows

$$
\begin{aligned}
& \delta\left(T^{*}\right)=\frac{g_{\mathrm{d}} d}{p_{1}-p_{2}} \\
& T^{*}=\frac{T_{1}+T_{2}}{2}
\end{aligned}
$$

where $d$ is the thickness of the envelope (wall), $g_{\mathrm{d}}$ is diffusion flux and $p_{1}, p_{2}$ are partial pressures of water vapour at both surfaces of the wall. Some researchers have attempted to "improve" the mentioned isothermal approximation $(1,2)$ by measuring $g_{\mathrm{d}}$ not in the isothermal state $T^{*}=T_{\mathrm{a}}$ but in non-isothermal conditions $T_{1} \neq T_{2} \neq T^{*}$. It is clear that in such a situation relations $(1,2)$ becomes incorrect and must be replaced by some different relations holding for the real non-isothermal state.

The aim of this paper is to derive the corresponding relations that govern the non-isothermal diffusion of water vapour through porous materials. The starting point for this derivation will be Fick's laws of diffusion.

\section{Non-isothermal diffusion of water vapours}

If there are no sources of diffusing particles and unidirectional steady state diffusion through a porous medium with diffusion constant $D$ has been established, then Fick's general equations can be rewritten in the simpler form

$$
\begin{aligned}
& q_{\mathrm{d}}=-D \frac{\mathrm{d} c}{\mathrm{~d} x}, \\
& \frac{\mathrm{d}}{\mathrm{d} x}\left(D \frac{\mathrm{d} c}{\mathrm{~d} x}\right)=0,
\end{aligned}
$$

where concentration $c$ of diffusing particles, i.e. molecules of water vapour, can be replaced by partial pressure $p$ and absolute temperature $T$, according to the equation of thermodynamic state

$p V=m R T, c=\frac{m}{V}, c=\frac{1}{R} \frac{p}{T}, \quad R \approx 462\left[\mathrm{Jkg}^{-1} \mathrm{~K}^{-1}\right]$.

Following the classical work of Schirmer [3] and Krischer [4] the diffusion constant $D$ of a porous building material is dependent on atmospheric pressure $p_{\mathrm{a}}$, temperature $T_{\mathrm{a}}=T$ and type of porous material which is represented by the diffusion resistance factor $\mu$ being a purely material constant. For "standard" pressure $p_{\mathrm{a}}=98066.5 \mathrm{~Pa}$, the diffusion constant $D$ can be expressed as follows

$$
\begin{aligned}
& D=8.9718 \cdot 10^{-10} \frac{T^{1.81}}{\mu}=\frac{k}{\mu} T^{\mathrm{n}}, \\
& n=1.81, \quad k=8.9718 \cdot 10^{-10}\left[\mathrm{~m}^{2} \mathrm{~s}^{-1} \mathrm{~K}^{-1.81}\right] .
\end{aligned}
$$

Inserting (5), (6) into (3), (4) Fick's equations will be modified

$$
\begin{aligned}
& q_{\mathrm{d}}=-\frac{D(x)}{R} \frac{\mathrm{d}}{\mathrm{d} x}\left(\frac{p_{(x)}}{T_{(x)}}\right), \\
& \frac{\mathrm{d}}{\mathrm{d} x}\left[\frac{k}{\mu R} T^{\mathrm{n}}(x) \frac{\mathrm{d}}{\mathrm{d} x}\left(\frac{p(x)}{T(x)}\right)\right]=0,
\end{aligned}
$$

with the following boundary conditions belonging to a non-isothermal wall of thickness $d$

$$
\frac{p(0)}{T(0)}=\frac{p_{1}}{T_{1}}, \frac{p(\mathrm{~d})}{T(\mathrm{~d})}=\frac{p_{2}}{T_{2}} .
$$

A linear temperature profile $T(x)$ inside the wall can be assumed, as follows

$$
T(x)=T_{1}-\frac{T_{1}-T_{2}}{d} x=a-b x .
$$

Inserting (10) into Fick's equations (7), (8) and taking into account the first boundary condition (9), the corresponding solution can be found

$$
\frac{k}{\mu R}(a-b x)^{n} \frac{\mathrm{d}}{\mathrm{d} x}\left(\frac{p}{T}\right)=-g_{\mathrm{d}}=\text { const. }
$$




$$
\begin{aligned}
& \int_{p_{1} / T_{1}}^{p(x) / T(x)} \mathrm{d}\left(\frac{p}{T}\right)=\int_{0}^{x}-\frac{g_{\mathrm{d}} R \mu}{k}(a-b x)^{n} \mathrm{~d} x, \\
& g_{\mathrm{d}}=\frac{\left(\frac{p_{1}}{T_{1}}-\frac{p_{(x)}}{T_{(x)}}\right) k b(1-n)}{\mu R\left[a^{1-n}-(a-b x)^{1-n}\right]} .
\end{aligned}
$$

Inserting the second boundary condition (9) into (11), we can express the steady state diffusion flux $g_{\mathrm{d}}$ going through the non-isothermal wall with the linear temperature profile (10)

$$
g_{\mathrm{d}}=\frac{\left(\frac{p_{1}}{T_{1}}-\frac{p_{2}}{T_{2}}\right) k b(1-n)}{\mu R\left[a^{1-n}-(a-b d)^{1-n}\right]} .
$$

The symbols $a, b$ in (14) can be specified using (10)

$$
g_{\mathrm{d}}=\frac{k(1-n)}{\mu R d} \frac{\left(\frac{p_{1}}{T_{1}}-\frac{p_{2}}{T_{2}}\right)\left(T_{1}-T_{2}\right)}{T_{1}^{1-n}-T_{2}^{1-n}} .
$$

Relation (15) can be rearranged and effective diffusion resistance $R_{d}^{*}$ and "conductivity" $D_{\text {eff }}^{*}$ may be introduced

$$
\begin{aligned}
& g_{\mathrm{d}}=\frac{c_{1}-c_{2}}{R_{\mathrm{d}}^{*}}\left[\mathrm{~kg} \cdot \mathrm{m}^{-2} \mathrm{~s}^{-1}\right], R_{\mathrm{d}}^{*}=\frac{d}{D_{\mathrm{eff}}^{*}}\left[\mathrm{~m}^{-1} \mathrm{~s}\right], \\
& D_{\mathrm{eff}}^{*}=\frac{k(n-1)\left(T_{1}-T_{2}\right)}{\mu\left(T_{2}^{1-n}-T_{1}^{1-n}\right)}\left[\mathrm{m}^{2} \mathrm{~s}^{-1}\right]
\end{aligned}
$$

where $c_{1}=\frac{p_{1}}{R T_{1}}\left[\mathrm{~kg} \mathrm{~m}^{-3}\right], c_{2}=\frac{p_{2}}{R T_{2}}\left[\mathrm{~kg} \mathrm{~m}^{-3}\right]$.

By means of relations (16) non-isothermal diffusion flux is easily available. As can be seen, the relevant potentials responsible for diffusion movement are not the partial pressures $p_{1}, p_{2}$ but concentrations $c_{1}, c_{2}$ of the water vapour at both wall surfaces. The differences between the non-isothermal diffusion fluxes determined according to rigorous relation (16) and that of isothermal approximation $(1,2)$, utilizing effective temperature $T^{*}$, ranges from several per cent to several tens of per cent, depending on the boundary conditions.

For completeness, the partial pressure profile $p(x)$ inside the wall should be analyzed. Function $p(x)$ is given by Eqs. (10), (13) and (14)

$$
\begin{gathered}
p(x)=\left(T_{1}-\frac{T_{1}-T_{2}}{d} x\right) \cdot \\
\cdot\left[\frac{p_{1}}{T_{1}}-\left(\frac{p_{1}}{T_{1}}-\frac{p_{2}}{T_{2}}\right) \frac{T_{1}^{1-n}-\left(T_{1}-\frac{T_{1}-T_{2}}{d} x\right)^{1-n}}{T_{1}^{1-n}-T_{2}^{1-n}}\right],
\end{gathered}
$$

for $n=1.81$ relation (17) will read

$$
\begin{gathered}
p(x)=\left(T_{1}-\frac{T_{1}-T_{2}}{d} x\right) . \\
\left.\cdot \frac{p_{1}}{T_{1}}-\left(\frac{p_{1}}{T_{1}}-\frac{p_{2}}{T_{2}}\right) \frac{T_{1}^{-0.81}-\left(T_{1}-\frac{T_{1}-T_{2}}{d} x\right)^{-0.81}}{T_{1}^{-0.81}-T_{2}^{-0.81}}\right] .
\end{gathered}
$$

At first sight it is obvious that the $p(x)$ profile is not linear. Nevertheless, for usual temperature and partial pressure differences between outdoor and indoor spaces in our climatic region the graph of $p(x)$ will closely follow the linear behaviour as depicted in Fig. 1.

\section{Conclusion}

This paper has presented the exact procedure (16) for calculation of the non-isothermal diffusion flux of water vapour going through porous materials. It has presented a comparison between the approximative procedure $(1,2)$ based on the

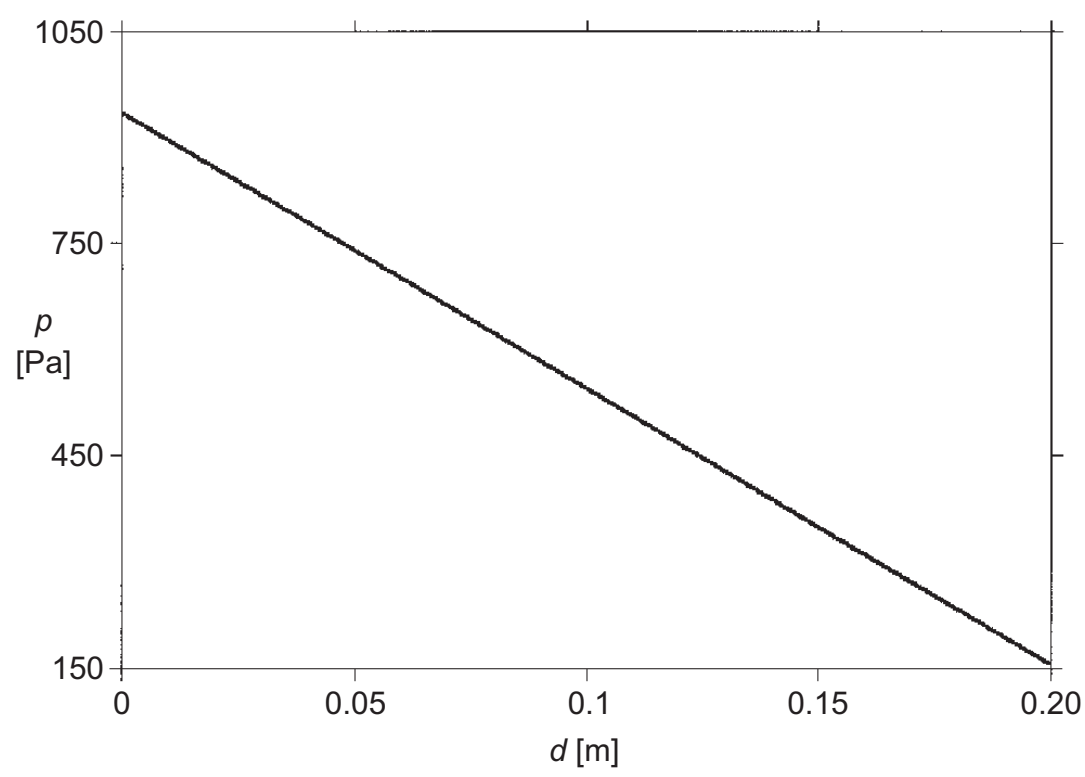

Fig. 1: Partial pressure profile $p(x)$ inside a wall of thickness $d=0.2 \mathrm{~m}$ with winter boundary conditions: $\varphi_{1}=40 \% \mathrm{RH}, T_{1}=293 \mathrm{~K}$, $p_{1}=934,8 \mathrm{~Pa}, \varphi_{2}=60 \% \mathrm{RH}, T_{2}=263 \mathrm{~K}, p_{2}=156 \mathrm{~Pa}$ 
concept of effective temperature $T^{*}$ and the exact procedure respecting the real non-isothermal conditions.

The corresponding non-isothermal pressure profile $p(x)$ inside the wall proved to be almost linear under climatic conditions that are normal in the Central European region (viz Fig. 1).

\section{References}

[1] Czech Thermal Standard ČSN 73 0540, Čs. normalizační institut, Praha 1994

[2] German Thermal Standard DIN 4108, Deutsches Institut für Normung, Berlin 1999

[3] Schirmer, R.: Diffusionszahl von Wasserdampf-Luftgemischen und die Verdampfungsgeschwindigkeit. Z.VDI-Beil., Verfahrenstechnik, No. 6/1938, pp. 170-177
[4] Krischer, O.: Grundgesetze der Feuchtigkeitsbewegung in Trockengütern. Kapillarwasserbewegung und Dampfdiffusion. Z.VDI-Beil. Verfahrenstechnik, No. 6/1938, pp. 373-380

Assoc. Prof. RNDr. Tomáš Ficker, DrSc.

phone: +420541147661

e-mail: fyfic@fce.vutbr.cz

Department of Physics

Ing. Zdenka Podešvová

Department of Building Structures

Faculty of Civil Engineering

University of Technology

Žižkova 17, 66237 Brno, Czech Republic 